\title{
Correction to: Models and Metadata: The Ethics of Sharing Bioarchaeological 3D Models Online
}

Priscilla Ulguim, School of Science, Engineering and Design, Teesside University, Middlesbrough, UK

E-mail: priscillaulguim@hotmail.com

\section{Correction to:}

Archaeologies: Journal of the World Archaeological Congress (ㄷ 2018) https://doi.org/10.1007/s11759-018-9346-X

The original version of the article unfortunately contained an error in Table 4 . The data in rows 2,3 , and 4 were inadvertently moved to the succeeding cells.

The corrected version of Table 4 is given below.

The original article has been corrected. 
Table 4 Comparison of guidelines and ethical statements on bioarchaeological and digital data (MD = metadata)

\begin{tabular}{|c|c|c|c|c|c|c|c|}
\hline Guideline & $\begin{array}{l}\text { Imagery/ } \\
\text { visual. }\end{array}$ & Copyright & $\begin{array}{l}\text { Digital } \\
\text { storage }\end{array}$ & $\begin{array}{l}\text { Digital } \\
\text { dissem. }\end{array}$ & Metadata & Format & Ethics \\
\hline $\begin{array}{l}\text { ADS Guide to Good } \\
\text { Practice } \\
\text { (Archaeology Data } \\
\text { Service and Digital } \\
\text { Antiquity 2011) }\end{array}$ & $\mathrm{Y}$ & $\mathrm{Y}$ & $\mathrm{Y}$ & $\mathrm{Y}$ & $\mathrm{Y}$ & $\mathrm{Y}$ & $\mathrm{N}$ \\
\hline $\begin{array}{l}\text { Dilmun Bioarchaeology } \\
\text { Ethics Statement } \\
\text { (Morgan 2013) }\end{array}$ & $\mathrm{Y}$ & $\mathrm{N}$ & Y (brief) & $\mathrm{Y}$ & $\mathrm{N}$ & Y (brief) & $\mathrm{Y}$ \\
\hline $\begin{array}{l}\text { BABAO Code of Ethics } \\
\quad \text { (BABAO 2010) }\end{array}$ & $\mathrm{Y}$ & $\mathrm{Y}$ & Y (brief) & $\mathrm{Y}$ & $\mathrm{N}$ & $\mathrm{N}$ & $\mathrm{Y}$ \\
\hline $\begin{array}{l}\text { WAC T-R Accord } \\
\text { (World } \\
\text { Archaeological } \\
\text { Congress 2009) }\end{array}$ & $\mathrm{Y}$ & $\mathrm{N}$ & $\mathrm{N}$ & Y (brief) & $\mathrm{N}$ & $\mathrm{N}$ & $\mathrm{Y}$ \\
\hline $\begin{array}{l}\text { WAC Vermillion } \\
\text { Accord (World } \\
\text { Archaeological } \\
\text { Congress 1989) }\end{array}$ & $\mathrm{N}$ & $\mathrm{N}$ & $\mathrm{N}$ & $\mathrm{N}$ & $\mathrm{N}$ & $\mathrm{N}$ & $\mathrm{Y}$ \\
\hline $\begin{array}{l}\text { WAC Digital } \\
\text { Bioarchaeological } \\
\text { Data (Hassett et al. } \\
\text { 2016) }\end{array}$ & $\mathrm{Y}$ & $\mathrm{Y}$ & $\mathrm{Y}$ & $\mathrm{Y}$ & $\mathrm{Y}$ & $\mathrm{Y}$ & $\mathrm{Y}$ \\
\hline $\begin{array}{l}\text { Human Tissue Act } \\
\text { (England) } 2004 \\
\text { (Human Tissue Act } \\
\text { 2004) }\end{array}$ & $\mathrm{N}$ & $\mathrm{N}$ & $\mathrm{N}$ & $\mathrm{N}$ & $\mathrm{N}$ & $\mathrm{N}$ & Y \\
\hline $\begin{array}{l}\text { 3D-ICONS (3D ICONS } \\
\text { 2014) }\end{array}$ & $\mathrm{Y}$ & $\mathrm{Y}$ & $\mathrm{Y}$ & $\mathrm{Y}$ & $\mathrm{Y}$ & $\mathrm{Y}$ & $\mathrm{N}$ \\
\hline $\begin{array}{l}\text { London Charter } \\
\text { (AAVV 2009) }\end{array}$ & $\mathrm{Y}$ & Y (brief) & $\mathrm{Y}$ & $\mathrm{Y}$ & $\mathrm{Y}$ & $\mathrm{Y}$ & $\mathrm{N}$ \\
\hline $\begin{array}{l}\text { Dublin Core project } \\
\text { metadata (DCMI } \\
\text { 2012) }\end{array}$ & $\mathrm{N}$ & As MD & As MD & As MD & $\mathrm{Y}$ & As MD & $\mathrm{N}$ \\
\hline $\begin{array}{l}\text { The Seville Principles } \\
\text { (International } \\
\text { Forum of Virtual } \\
\text { Archaeology 2011) }\end{array}$ & $\mathrm{Y}$ & $\mathrm{N}$ & $\mathrm{N}$ & $\mathrm{N}$ & Y & $\mathrm{N}$ & $\mathrm{N}$ \\
\hline
\end{tabular}

